\title{
Ip Intermediate Gradient and resistivity sounding application in anomalies evaluation of a tin polymetallic mining anomalies evaluation
}

\author{
Yubo Yang ${ }^{1, a^{*}}$, Zhongjun Deng ${ }^{1, b}$, Chenglin Yao ${ }^{1, c}$ and Yongmei Jia ${ }^{1, d}$
}

${ }^{1}$ Beijing IWHR Corporation, China Institute of Water Resources and Hydropower Research, Beijing 100048, China

ayangyb@iwhr.com, ${ }^{b}$ dengzj@iwhr.com, ${ }^{\mathrm{c} y a o c l @ i w h r . c o m, ~}{ }^{\mathrm{d} j i a y m @ i w h r . c o m ~}$

\begin{abstract}
Keywords: Induced polarization; Ip Intermediate Gradient; Resistivity sounding
Abstract. Activation polarization method apply the IP effect in different rock, ore as the foundation, an exploration method base on the observation and research IP effect of earth to detect underground geological conditions . Ladders can be found in the use of IP and IP anomalies of delineation of metal ores distribution, can be identified using induced polarization sounding polarized distribution of body. By studying an IP anomaly and its characteristics of Tin polymetallic mining area, than based on the known geological, geophysical data, in-depth geological, it provided a favourable basis for carrying out of prospecting work.
\end{abstract}

\section{Geology}

\section{Formation}

Single workspace strata outcropped, mainly on the Mesozoic Jurassic Zhangjiakou group $\left(\mathrm{J}_{3} \mathrm{Z}\right)$ and quaternary (Q). The former is composed of quartz of trachyte, trachyte, little spot, spot, spot-like structure, is no local spots aphanitic structures, massive structure. The latter is mainly located in the Northwest area of the mountain hollow and gullies and alluvial and deluvial sandy clay, fine sand, etc, covered Aeolian sand, thickness up to about 10m.

\section{Magmatic rocks}

Magmatic rocks are mainly hypabyssal intrusive granite, granitic porphyry (lambda PI 52 (3)), mainly exposed in the southeast edge of exploration zone, and the exploration area, west of invading the second rock section in Zhangjiakou group trachyte, quartz trachyte. The porphyritic structure, coarse grain structure, block structure.

\section{Structure}

Joints are main structural forms widely distributed in exploration area. Joint property is mainly shear extensional, northwestward.

Fracture zone is mainly distributed in the workspace south east, north, west, distribution is discontinuous, and secondary parallel fracture zone is associated. Different degrees of silicide fracture zone east of south east development, accompanying tungsten tin polymetallic mineralization; North West zone is given priority to with petrochemical complex, deep associated with pyrite, chalcopyrite mine.

\section{Rock ore electrical characteristics}

In order to know each kinds of rock characteristics of chargeability in the working area, the exposed rock samples collected in work area to determine physical properties. Rock ore in the area of the polarization rate was the highest in polymetallic ore, average by $4.9 \%$; Tungsten quartzite in second place, average is $3.1 \%$; And as the main body of trachyte in bedrock polarization rate is only $2.1 \%$, low but when its metallogenic geological process and silicified alteration occurs, the polarization rate increased, the average of $2.7 \%$. The fluorite ore for all kinds of rock ore in the polarization in the lowest, but has a larger range, polarizability values ranged from $0.9 \%$ to $3.3 \%$.

In metal ore has high polarizability, when it has a certain size, will cause high strength apparent chargeability anomalies; Fluorite ore chargeability value range is larger, the fluorite mineralization zone can appear high value anomaly, may also appear abnormal low; Trachyte polarization rate is not high, will show the apparent chargeability background field, but after the alteration chargeability 
value subsequently heighten, likely intensity weaker apparent chargeability anomalies; Therefore in this work area using induced polarization method for deep polymetallic mineralization is feasible.

In addition, the resistivity of rock ore is related to its material composition and structure, but with the moisture content of high and low and there is close correlation between, in general, fracture structure will become apparent resistivity is relatively low; And in terms of tin polymetallic mineralization bodies in this area, by the characteristics of geology and mineral resources of knowledge, they are controlled by fracture structure on the one hand, filling in the fractured zone, as an electrical conductor metal minerals will make its conductivity enhancement; By strong silicification again on the other hand, the higher resistivity, a result of the combined action of both tin polymetallic mineralization body is characterized by medium resistivity characteristics.

\section{Working method and technology}

\section{Work deployment}

According to regional geology and combining with geological task, the IP of ladder line layed out vertical to the north east, line distribution is parallel, the line is apart from the $100 \mathrm{~m}, 20 \mathrm{~m}$ distance; Infill area line from $50 \mathrm{~m}, 20 \mathrm{~m}$ distance. Framed design for correct work area is unusual, in practical exploration work on area measurement on the basis of the scope of the original design made a certain extend. Select the IP sounding method as an auxiliary method, used to check the infill zone area of abnormal work.

The electrical prospecting using induced polarization method, including the intermediate gradient device for the area of sex work, sounding using symmetrical quadrupole device. IP sounding work main arrangement in the ladder in the IP scanning results are chosen after a comprehensive analysis of metallogenic meaningful IP anomaly area, the purpose is to know the concealed buried depth, shape and occurrence of anomalous body state.

\section{Device parameters}

This IP ladder working power supply polar distance is $1800 \mathrm{~m}$, the power supply current is not less than $3 \mathrm{~A}, \mathrm{~A}, \mathrm{~B}$ pole power supply electrode with the method of circular permutation, electrode for A total of 50-60 root, adjacent power pole pitch with electrodes buried depth. Measuring polar distance of $40 \mathrm{~m}$, receive pole adopts solid non-polarizable electrode. The duty ratio is 1:1 two-way short pulse power supply, power supply pulse width +4 seconds, cycle 16 seconds, acquisition delay $100 \mathrm{ms,}$ integral area of $50 \mathrm{~ms}$, synchronously using the synchronization.

The IP sounding symmetrical quadrupole device for the work, power supply and receiving parameter is set the same as the IP of the ladder. But power supply electric current on power pole pitch and measure the size of the pole pitch have been adjusted. Power supply polar distance AB / 2 and receive pole pitch $\mathrm{MN} / 2$ pole pitch changes are shown in table 1.

Table 1 Distance table of resistivity sounding (unit: $\mathrm{m}$ )

\begin{tabular}{c|c|c|c|c|c|c|c|c|c|c|c|c|c|c|c}
\hline $\mathrm{AB} / 2$ & 3 & 6 & 9 & 15 & 22 & 32 & 45 & 60 & 85 & 120 & 180 & 250 & 350 & 500 & 750 \\
\hline & 1 & 1 & 1 & 1 & 1 & \multicolumn{10}{|c}{} \\
\cline { 2 - 15 } \\
\cline { 2 - 12 }
\end{tabular}

\section{Data interpretation}

\section{The apparent resistivity distribution characteristics}

From the apparent resistivity plane contour map (Fig.1) as we can see, in the apparent resistivity isopleth subject appear nearly NW to the characteristics of distribution, in the apparent resistivity from southwest to northeast overall performance for the characteristics of high and low distribution. By the field survey of apparent resistivity is more than 1400 high value area partitioning's bedrock exposed area or location, with thin quaternary sediments and the apparent resistivity of low-value area is distributed in the quaternary sediments of the thicker sections, that is to say, in the discretion of the apparent resistivity changes with the thickness of the quaternary sediments, they have close 
relation, namely, , the greater the quaternary sediment thickness the lower the apparent resistivity is, and vice versa. But in apparent resistivity is extremely low, besides the impact of the thick quaternary system, also did not rule out the fault fracture zone caused by the stack effect.

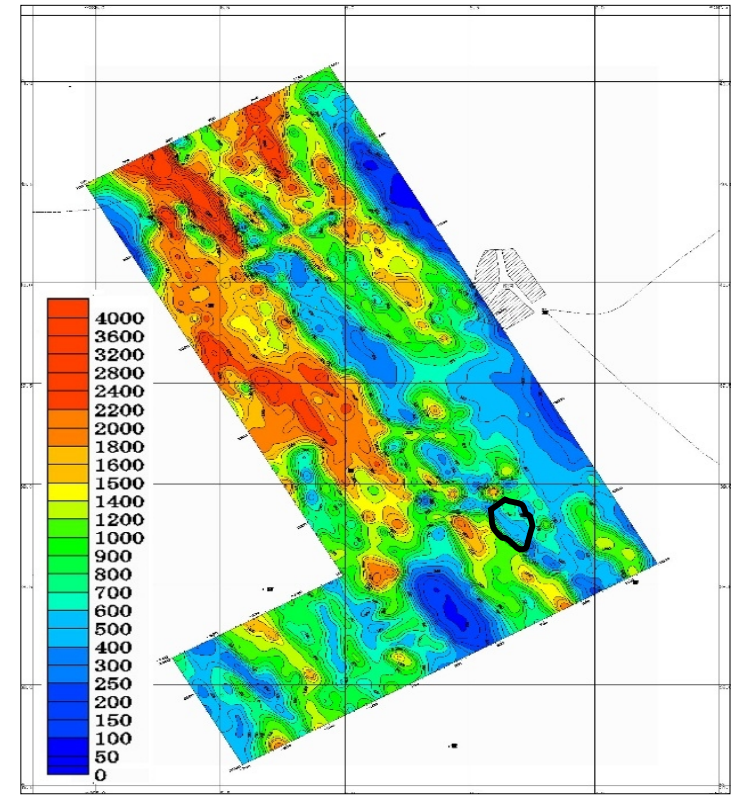

Fig.1 Apparent resistivity planar isoline

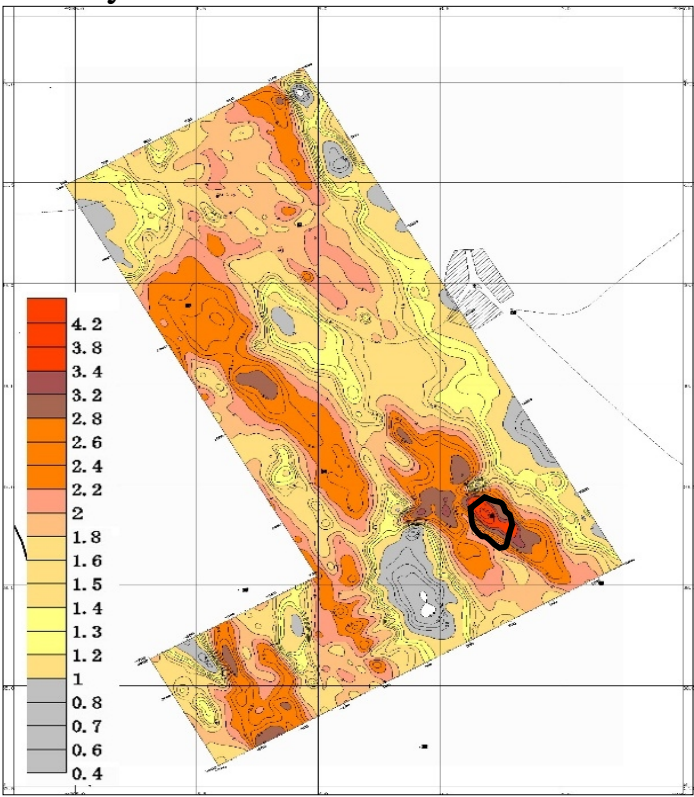

Fig.2 Depending on the polarization plane contour map

\section{Apparent polarization distribution characteristics}

From apparent chargeability plane contour map (Fig.2) can be seen: apparent polarizability is less than $2 \%$ of the area, constitute the background of this district is apparent chargeability same performance as the main body in the contour appear nearly NW to the characteristics of the distribution. Apparent chargeability from southwest to northeast in overall performance for the distribution of the high and low and characteristics. Apparent polarizability is greater than $2 \%$ of the high value area partitioning's bedrock exposed area or location, with thin quaternary sediments and low apparent polarizability of the area is distributed in the quaternary sediments thicker sections. But in the high value of the apparent polarizability and low background area in local high value sections besides the influence of the quaternary thickness is small, does not rule out mineralized alteration superposition effect does exist.

\section{Anomaly interpretation}

The anomaly center near 960/2900 1000/2600 points in northwest area (see Fig.1, Fig.2 lower right corner), the abnormal area has apparent resistivity abnormal low area (apparent resistivity minimum value is lower than 250) and apparent polarizability of high value area (maximum apparent chargeability value is greater than $4 \%$ ) and at the same time.

To understand the deep mineralization of abnormal area, set up an abnormal area in IP sounding profile, the profile of the sounding data inversion results shown in Fig.3 and Fig.4. Fig.3 shows the extent of shallow for low resistance layer, the resistivity is less than 120 , is a reflection of the quaternary sediments, the layer thickness at 860 meters north is several meters building up to about $20 \mathrm{Ohm}$ meter near 1100. Below v resistance layer resistivity between $120 \mathrm{Ohm}$ meter $\sim 520 \mathrm{Ohm}$ meter, should be caused trachyte, the thickness of trachyte from southwest to northeast gradually become smaller, since 860 about 250 meters north gradually thinning to near 1100 about 170 meters. The layer below the high resistance layer, the resistivity is more than $520 \mathrm{Ohm}$ meter, it is possible that integrity good granite porphyry. Can be seen from Fig.4, after inversion polarizability anomalies is obvious narrow, abnormal center at 900 points, the polarization anomalies caused by mineralized alteration zone, the zone is a nearly erect slightly to the north east pour plate, its width is not more than $40 \mathrm{~m}$, about $50 \mathrm{~m}$ top buried depth and mineralized alteration zone into the inner contact zone of granite porphyry, about $300 \mathrm{~m}$ depth. That is to say, the abnormal area good metallogenic prospects. 


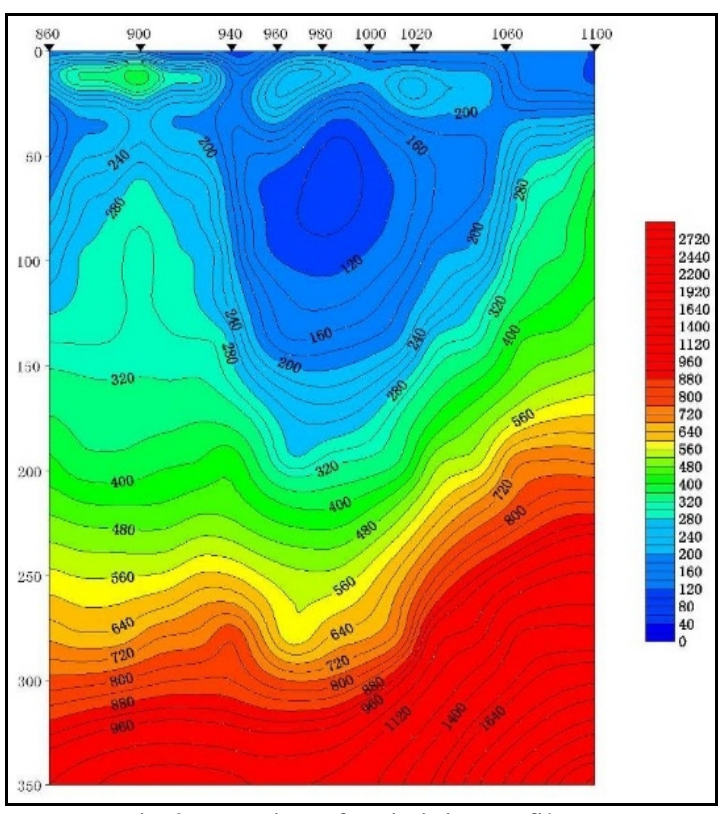

Fig.3 Inversion of resistivity profile

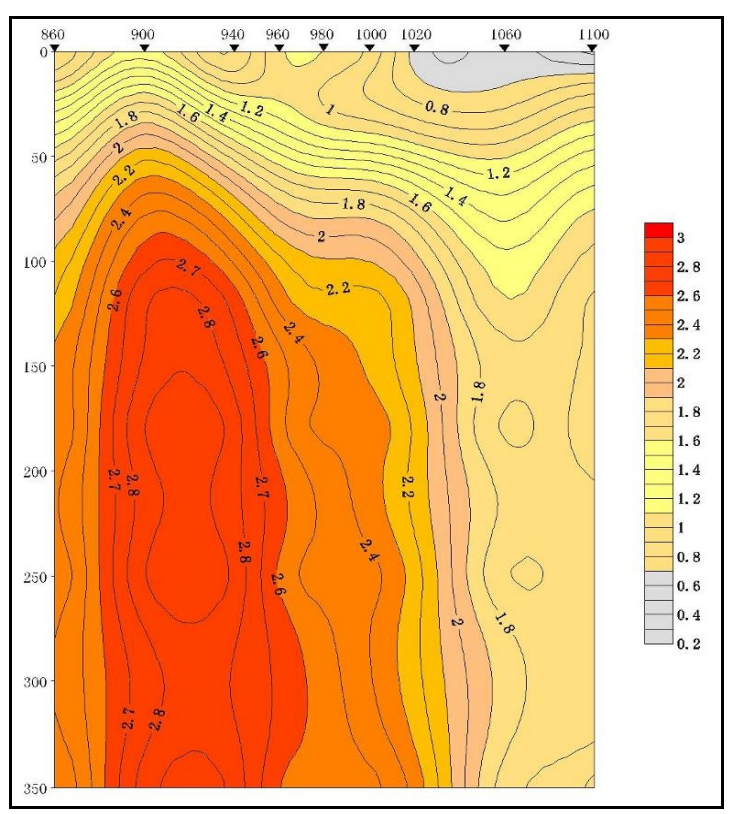

Fig.4 Inversion susceptibility profile

\section{Conclusion}

The geophysical anomaly zone is mainly with low resistance and high polarization. Through the anomaly form system verification, form of anomaly zone is real, and in accordance with alteration mineralization geological body of mining area, that geophysical exploration work can more objectively reflect the actual situation of mine geological and mineralization. In the exploration of concealed or deep polymetallic minerals, metals within the mining area induced polarization methodand altered rocks have good reflection, and to guide provides a sufficient basis for engineering verification.

\section{References}

[1]Liu Rui-de, Huang Li-jun, Yang Jin, et a1. The application instance of synthesis electrical methods to the exploration of metallic ore deposits[J] . Geophysical and Geochemical Exploratian, 2006, 30(4): 322-326.

[2]Luo Zhi-feng. Application of induced polarization technique to exploration of porphyric copper deposit [J]. Contributions to Mineral Resources and Geology, 2003, 12(Suppl. 1): 149-151.

[3]Jin Yan-feng, Zhang Chuan-le, Kou Xiu-feng. The Mo ore-forming and geological features in the middle West, Yanbian area [J]. Jilin Geology, 2004, 23 (3): 53-59.

[4]Yang Li-gong. Application of IP charge method for metal deposit prospecting [J]. Mineral Resources and Geology, 2003, 17(1): 36-38.

[5]Pirajno, Franco, Bagas, Leon. A review of Australia's Proterozoic mineral systems and genetic models [J]. Precambrian Research, 2008, 166(1-4): 54-80.

[6]KOTA WATANABE, YOSHINORI TAKA, OSAMU FUJIWARA. Cole-cole Measurement of Dispersion Properties for Quality Evaluation of Red Wine [J].Measurement Science Review, 2009, 9(5):113 